\title{
Developing Children with Special Needs Through Love, Understanding and Rationality.
}

\author{
Nipa Samitasiri ${ }^{1}$
}

\begin{abstract}
Children with Special Needs refers to a specific group of children and youngsters who require additional assistance due to their physical, mental and/or intellectual disabilities and limited physical development. And Special Educational Need: SEN is one of their usual requirements. Additional assistance is to be given to those with impaired visibility, impaired audibility, Short Attention Disorder and multiple disabilities.

Special Needs refers to additional support and assistance specifically given to this group of youth by surrounding people such as their family members, their teachers and classmates at school. So they can perform their daily tasks and pursue their studies like everyone else.

To state an example, Ramkamhaeng University students with impaired audibility have shown improvement in their studies after participating in science-based activities: creating scientific picture frames. Engaged in social activities, they have more social interaction and communication with their classmates and teachers. They have become more supportive for one another. And due of the moral and academic support they mutually get, they perform better in class. Some even got an academic honour.

Offering additional assistance to these youngsters is important and the family and society shall be fully aware. For the parents, choosing a right school for them is one of the priorities. The school should provide proper education and care with the suitable teaching and learning approaches in order to encourage their development and progress. Teachers also play an important role in assisting and resolving problems. They should understand each individual's nature so that they can adjust their teaching methods and techniques to motivate the student to learn. Teachers should also be sensitive and attentive to students' requirements and limitations. Students should be encouraged to do what they are good at so they can be proud and think positively about themselves. This will encourage them to live happily in the society, not feeling they are a burden to other people.
\end{abstract}

Key Words: Children with Special Needs, Developing Children with Special Needs

\section{Introduction}

Special groups of children or formally known as Children with Special Needs are children and youngsters whose abilities and skills cannot be fully developed through generally practiced parenting and teaching and learning approaches. This is due to their limitations and conditions which include intellectual, hearing and visual impairment, autism, physical disabilities, multiple disabilities, etc. Some have communication problems, impaired emotional expressions, disruptive behavioral patterns, social adjustment struggle. So we need to use special measures and teaching methods that can accommodate and encourage them to learn more effectively especially about their 
sensory skills. They may need additional equipment and tools different from what is provided to general children. This is to help them effectively learn and fully develop their capabilities.

Having these children in a family certainly affects the family members. They may be in shock,(Peterson,1987)[1] in denial and even feel depressed having to take care of the children.(Bristol,Gallagher,\&Schopler,1988)[2] They then become extra work loads for the family.

Handling children with special needs, we need to consider each individual's conditions and requirements. The family plays an important role and has influence on them. They should handle them with love, understanding and moral support so that they feel motivated to learn.

One outstanding case is Miss Viriya WIwatarangkul, a Ramkamhaeng University student with partial hearing disability. Wearing a hearing aid, she still managed to get a Magna Cum Laude (2nd class honor) from the Faculty of Political Science. She comes from a warm and understanding family, always supportive of her pursuit of study. And through participation in the research project of using science-based activities to adjust learning behavior of handicapped students at Ramkamhaeng University, they have met many more friends who have the same conditions. They have got to know more about facilities on campus. This helps them become more tolerant and have better problem-solving skills. They have learned to communicate with their classmates by sing language via mobile phones, searching for free tutoring sessions on campus. They have also managed to find additional teaching materials as recommended by their friends. As a result, they understand the lessons better and their learning behavior has improved.

This phenomenon is evidently in accordance with Classic Conditioning Theory that states human beings tend to notice similar arousals and respond similarly (Chaiwat Sittirat, 2009, p.19-20).[3] Dealing with difficulties and problems rationally helps the family members overcome stress and tension. The following are contributing factors that determine the levels of stress the family has to deal with: (McCubbin \& Patter,1983)

1. The conditions of the disabilities. The more requirements the child has, the more tension the family has to encounter.

2. Support given to the family. This includes mutual love, understanding and moral support for one another and support form organizations and agencies that provide counseling, training and techniques about caring for the children with special needs.

3.The family's attitude. Some families view having children with special needs is some kind of shame and embarrassment while others see this as a challenge. Different family backgrounds lead to different treatments given to these children. [4]

Study Approaches : for children with special needs

1. Normalization: a provision of teaching and learning environment that looks and feels as normal as possible.

2. Deinstitutionalization: Releasing children with special needs from the institution to be back in the society, living with other people in their community.

3. Mainstreaming: Children with special needs co-exist and study with other normal children in the same class.

4.Individualized Educational Plan )IEP)should be implemented since they have 
different levels of capability and readiness. The study program should be flexible and adjustable to suit their conditions. children.
5. The parents should be fully aware and take lead in providing education to the

6.Medical services should be provided together with educational ones to help ease their difficulties and to facilitate their learning progress. These include therapeutic activities, mental exercises, speech correction, physical therapy and others.

7.A provision of education should be implemented at the earliest stage as possible. Pre-schooling education is a priority. (Oranuch Limtasriri,2011,pp.5-6)[5]

All in all, Individualized Educational Plan )IEP) should be based on the children's backgrounds since they have different levels of physical, mental, emotional, social and intellectual development. They also need to learn to keep abreast of the changing world. With their unique capabilities, education will sharpen the children's skills and talents. The teaching and learning approaches and processes should be different from those used for other normal children to fully help them progress academically. One example is participating in science-based activities which is a new skill helps them become more enthusiastic and have an opportunity to meet new friends who have the similar conditions. It is found out that 4 out of 14 participants have shown outstanding learning behaviors after attending the science- based activity for handicapped students at Ramhamhaeng University. (Wanida Chatrawirakom and Nipa Samitasiri 2015, P.53).[6] This results in the smaller number of students registering for re-exam and the first semester of the 2015 academic year.

\section{Special Educational Services}

Educational and teaching and learning services provided in addition to lectures in classes. They include (Padun Arayavilyu, 2006, p16).[7]

1.Speech correction : for children with articulation and pronunciation difficulties, hearing impairment, intellectual and physical disabilities.

2.Counseling services for all disabled children to ease their difficulties in social adjustment.

3. Psychiatric services: for children with behavioral problems, intellectual disabilities and other special needs.

4.Physical therapy: for children who have problems with mobility to help develop the strength of their muscles and joints for better body coordination and balance.

5. Activity Therapy: Activities for children to help improve the movement of hands and fingers in order for them to be able to do their daily activities and tasks.

In conclusion, Special Educational Services are especially arranged for these children in addition to lectures in class. This requires integration of interdisciplinary approaches and practitioners including their own families, the class teacher, the counselor, psychiatrist, sensory therapist, physical therapist, occupational therapist and specialized doctors. They can diagnose, analyse and plan the treatment program to help these children become competent to work professionally. So that they can work and live normally and happily with others in the society. 
Psychological approaches to be used when teaching: offering assistance

Children with behavioral problems display aggression, disruptive and disturbing behaviors. This results from discrepancy between their state of being and their circumstances. And their struggle in learning derives from their conflicting emotional state. Support and assistance to be given are based on the following.

1.Educational Psychology approaches. Psychologists believe biological factors and parenting approaches of their families affect the personality development as well as their emotional state. All kinds of discrepancy stem from inappropriate personality development. One solution to this is to let them realize their own problems and have a will of their own to fix them. Dealing with their own problems, they should be motivated and have faith in themselves. So teaching and learning approaches should be adjusted and designed specifically to fit each and individual's requirements.

2. Psychological approaches. Behavioral development approach can be used to lessen the undesirable behaviors. They can learn through observing the well-behaved ones. So the focus should be put on the desirable behaviors only.

3. Ecological approaches. The children are part of the society and the school. And since school is part of the society, their behaviors should be accepted by others in the society. Behavioral development approaches include:

3.1 Positive reinforcement. This can be done verbally i.e. praise them when they do something right and nice, reward them with snacks, sweets, toys, etc.

3.2 Negative reinforcement. When they do not do their homework, they are reprimanded by the teacher. But when they do, the teacher dos not reprimand them. Then they will tend to do their homework afterwards.

3.3 Punishment and redemption for their improper behavior. They are punished and given additional work as their redemption. One sample is when they make a mess in their classroom, they will be asked to tidy things up and then assigned to arrange the desks and tables in the classroom.

3.4 Being a good role model. All surrounding adults should be well-behaved so they can take those as their role models and follow the desirable behaviors such as being polite, hardworking and well-organized.

Now that children with special needs gain more awareness and acceptance in the society. We should provide and implement the following treatment and care for them so as to help them study more effectively and develop their capabilities to the fullest:

1. Care with love. Love has a magically healing power which helps encourage and motivate them to do better. Through love, their stress, anxiety, paranoid and boredom will be lessened. They will have more mental stability and encouragement to think logically and creatively leading to progress in all areas.

2. Intellectual development is a basic skill to be trained. They should learn to read, write, calculate and memorize.

3. Development of self-dependency. They should be trained to perform their daily activities and tasks on their own such as bathing, teeth brushing, eating and tidying things up. This takes time and perseverance. They should not be pressured until they do not feel like doing. The children should be gradually and continuously trained so that they will be able to live normally in the society. 
4..Adjusting the environment that accommodates and encourages their learning. This is an essential part to help enhance their skills. With individualized learning program, those with specific needs such as with behavioral problems, with multi disabilities, with intellectual disability do not need to attend extra classes. However, they should be provided with the least restricted environment so that extra classes is not a necessity. And other normal students and the children with minor disabilities then can attend the same classes together. This then will help with their social adjustment.(Taweesak Sririratrekha,2006,pp.2-8)[8]

Having these children learn to do recreational activities that they love helps improve their self-reliance. Playing a musical instrument, singing, drawing and crafting help enhance their creativity. To support this is the case of Ramkamhaeng University students who have realized they enjoy this kind of activity after having voluntarily participated in an activity in which they are interested. As stated in Srisuk Sujirakul (2008, p.68).[9] They all would like a provision of recreational activities on campus. Also from Wanida Chatrawirakom and Nipa Samitasiri 's research ( 2015, P.61)[10], they have shown a good level of participation in the science- based activity: creating picture frames. 7 out of 14 students' performance has been rated as above average. In addition, they also would like this kind of recreational activities to be offered. So we should use positive reinforcement and encouragement to motivate these children's participation. As a result, their logical thinking and mental state will positively develop.

\section{Conclusion}

From my experience as a teacher who is close to these children, I have realized all of them can develop themselves through time, love and understanding, patience and perseverance. They should be guided, not reprimanded when doing something wrong. They should not feel guilty or pressured, but loved and welcomed. They should be provided with recreational activities and skill trainings so that they can fully develop. With constructive activities and positive comments, they will feel more confident and content living in the society.

\section{References:}

[7]Arayavilyu,P.(2006). Education for Special Students. Bangkok:Ramthai Pression.

[2]Bristol, M.G., Gallagher, J., \& Schopler, E. (1988). Mothers and Fathers of Young

Developmentally Disabled and Nondisabled Boys : Adaptation and Spousal Support.

Developmental Psychology.

[10]ChatwiraKom,W. and ,Samitasiri,N. )2016(. Using Scientific Activities to improve the

Learning Behavior of Disabled Students in Ramkhamhaeng University. Research Project,

Faculty of Education, Bangkok : Ramkhamheang University.

[5]Limtasriri,O.(2011).Teaching Special Student.Bangkok: Ramkhamhaeng University.

Press.

[4]McCubbin, H., \& Patterson, J. (1983). The Family Stress Process: The Double ABCX Model of

Adjustment and Adaptation. Marriage and Family Review, b.

[1]Peterson, N. (1987). Parenting The Young Handicapped and At-Risk Child. In N. Peterson (Ed.),

Early Intervention for Handicapped and At-Risk Children: An Introduction to Early 
Childhood Special Education. Denver, Colo: Love

[3]Suthirat,C. (2009). 80 Innovations for Student-based Activities. Bangkok: Daenext Inter-Corporation Company Limited.

[9]Sujirakul,S. (2008).The Meeting of Basic Needs in Educational Programs for

Physically Challenged Students at Ramkhamhaeng University. Research Project, Student Affairs, Office of the President, Ramkhamhaeng University.

[10]Sririratrekha,T.(2006).Playing for learning of the Autistic students.Bangkok: Krurasapa Laopoo press. 